\title{
Behavioral aspects of communication in organizations
}

Citation for published version (APA):

Casoria, F., Riedl, A., \& Werner, P. (2020). Behavioral aspects of communication in organizations. Maastricht University, Graduate School of Business and Economics. GSBE Research Memoranda No. $010 \mathrm{https}: / /$ doi.org/10.26481/umagsb.2020010

Document status and date:

Published: 19/03/2020

DOI:

10.26481/umagsb.2020010

Document Version:

Publisher's PDF, also known as Version of record

\section{Please check the document version of this publication:}

- A submitted manuscript is the version of the article upon submission and before peer-review. There can be important differences between the submitted version and the official published version of record.

People interested in the research are advised to contact the author for the final version of the publication, or visit the DOI to the publisher's website.

- The final author version and the galley proof are versions of the publication after peer review.

- The final published version features the final layout of the paper including the volume, issue and page numbers.

Link to publication

\footnotetext{
General rights rights.

- You may freely distribute the URL identifying the publication in the public portal. please follow below link for the End User Agreement:

www.umlib.nl/taverne-license

Take down policy

If you believe that this document breaches copyright please contact us at:

repository@maastrichtuniversity.nl

providing details and we will investigate your claim.
}

Copyright and moral rights for the publications made accessible in the public portal are retained by the authors and/or other copyright owners and it is a condition of accessing publications that users recognise and abide by the legal requirements associated with these

- Users may download and print one copy of any publication from the public portal for the purpose of private study or research.

- You may not further distribute the material or use it for any profit-making activity or commercial gain

If the publication is distributed under the terms of Article $25 \mathrm{fa}$ of the Dutch Copyright Act, indicated by the "Taverne" license above, 
Fortuna Casoria, Arno Riedl, Peter Werner

Behavioral aspects of communication in organizations

RM/20/010

\section{GSBE}

Maastricht University School of Business and Economics

Graduate School of Business and Economics

\section{P.O Box 616}

NL-6200 MD Maastricht

The Netherlands 


\title{
Behavioral aspects of communication in organizations
}

\author{
Fortuna Casoria ${ }^{1}$ \\ Arno Riedl ${ }^{2}$ \\ Peter Werner ${ }^{3}$
}

February 2020

\begin{abstract}
This paper reviews experimental studies that investigate the effects of communication on behavior in organizational settings. Two main classes of studies are identified: (a) studies on coordination and competition, which include experimental research that tests whether communication can help to overcome coordination failure within organizations, and (b) studies that analyze the role of communication in alleviating problems arising from information asymmetries at the workplace. The evidence from these studies indicates that communication is suited to improve efficient coordination within firms and to mitigate information problems in employer-employee relationships. In addition, studies are presented that focus on the interaction between communication and monetary incentive schemes in companies.
\end{abstract}

Keywords: Communication, organization, experiment, behavior

JEL Classification: C90, D82, D83, J53

\footnotetext{
${ }^{1}$ University of Lyon, CNRS, GATE UMR 5824, F-69130 Ecully, France. E-mail: casoria at gate.cnrs.fr

${ }^{2}$ CESifo Munich, IZA Bonn, Netspar Tilburg \& Department of Microeconomics and Public Economics, School of Economics and Business, Maastricht University, P.O. Box 616, NL-6200 MD Maastricht, The Netherlands. E-mail: a.riedl at maastrichtuniversity.nl

${ }^{3}$ Department of Microeconomics and Public Economics, School of Economics and Business, Maastricht University, P.O. Box 616, NL-6200 MD Maastricht, The Netherlands. E-mail: p.werner at maastrichtuniversity.nl
} 


\section{Introduction}

Communication is an important element of the interaction in the workplace and can crucially determine the success of an organization. This has been widely recognized by research in the field of management. For example, Harris and Nelson (2007) point out the decisive role of communication describing it as "one of the most dominant activities occurring in any work setting" (p.12). Hutchinson (2014) argues that communication in the context of human resource management practices may help to clarify the organization's goals for the employees, to increase the employees' commitment and to strengthen the relationship between the employer and the employees. Den Hartog et al. (2013) maintain that the views of managers and employees on human resource management practices are more aligned when the communication between these two groups is of high quality, meaning that managers communicate sufficiently, that the information conveyed is useful, and that it is properly understood by the employees.

In the economic analysis of strategic interactions at the workplace, communication between players often has a "cheap talk" character, in the sense that messages do not have a direct effect on the payoffs associated with different strategies. Yet, in experimental tests this kind of communication is found to be very effective in changing behavior which in turn can affect the payoffs of the interaction partners (Farrell and Rabin, 1996). Economic theory has provided important insights into the role of communication, both for strictly rational and boundedly rational players. For instance, it has been shown that private information about interaction partners can be revealed in equilibrium, provided the incentives of the involved parties do not create too severe conflicts of interests (Crawford and Sobel, 1982; Crawford, 1998). Moreover, communication makes it possible for boundedly rational players to coordinate better and achieve higher average payoffs in games with common interests, such as stag-hunt games (Ellingsen and Östling, 2010). At the same time, it has been argued that depending on the type of game, communication flows (e.g., either one-sided or two-sided communication) may crucially determine its influence on coordination success.

There is also empirical experimental evidence that the possibility for decision-makers to communicate with each other has a substantial impact on efficiency and payoff allocations in a variety of economic settings. Communication has been found to enhance cooperation in social dilemma experiments (Balliet, 2010, provides a meta study of the literature), to significantly affect altruistic behavior (see, e.g., Charness and Rabin, 2005; Mohlin and Johannesson, 2008; Andreoni and Rao, 2011), and to foster coordination (see, e.g., Cooper et al., 1992; Charness, 2000; Duffy and Feltovich, 2002, 2006; Blume and Ortmann, 2007). Bolton et al. (2003) find that the organization of communication flows significantly affect the outcomes achieved in coalitional bargaining and Brandts et al. (2016) show that communication affects contract choices. Furthermore, communication has been found to affect behavior in strategic market entry games. In a limit pricing game, Cooper and Kagel (2005) report that teams who are able to communicate with each other exhibit stronger strategic play than individuals. In a related study, the same authors observe higher frequencies of strategic play in teams with two-sided communication compared to an advisor-advisee treatment in which only one-sided communication is possible (Cooper and Kagel, 2016). These latter results highlight the relevance of the exact nature of the communication process for its effectiveness. As it is often difficult to incorporate the communication process in theoretical models, due to its complexity in strategically rich environments, experimental studies are an important vehicle to gain an understanding in that respect (Brandts et al., 2019, provide an extensive survey among other things on the effects of the communication process on behavior in experimental studies).

Many studies listed so far do not explicitly refer to company settings. Still, an increasing number of experimental studies has focused on the role of communication in interactions within 
organizations. The experimental approach is especially well-suited for this purpose for at least the following reasons. First, the effects of communication on behavior are difficult to study with observational field data (for instance, company data), as it is basically impossible to reliably track communication patterns between colleagues or between managers and team members. Second, the alternative of using surveys to get insights into the communication patterns and contents between managers and employees also has some shortcomings. For instance, data from surveys might be noisy and inconsistent due to the lack of explicit incentives to think carefully about potential answers. Survey answers about the role of communication within the organization also might not provide the correct picture because of socially desirable answers (e.g., if employees are asked about the way their supervisors communicate with them).

Experiments circumvent some of these problems by providing explicit performance based incentives and by controlling the way communication can take place as well as by restricting the feasible communication content. Regarding the role of communication in organizations mostly laboratory experiments and a few field experiments have been been conducted. Both types of experiments have their advantages and disadvantages (for a discussion, see, e.g., Harrison and List, 2004; Levitt and List, 2007; Falk and Heckman, 2009; Levitt and List, 2009) and should be viewed as complementary approaches in gaining insights into the role of communication at the workplace.

This paper focuses on studies related to the topics "coordination and competition" and "asymmetric information" because those are of central relevance for processes within organizations. Coordination of activities is key to achieve the goals of organizations in which a large number of members take independent but interactive decisions. The degree to which coordination can be successfully achieved depends on incentives. In some cases, the incentives of agents are aligned so that everyone profits from successful collaboration, making it relatively easy to achieve coordinated behavior that is also in line with the organization's interest. In other circumstances, agents or organizational units compete against each other, which may lead to uncoordinated actions and outcomes that are not necessarily benefiting the organization. Information asymmetries are a central barrier in the interaction at the workplace as the interests of employers and employers may often be in conflict. Problems arise because the actions of one party cannot be (fully) observed by the other party (such as the effort exerted by the worker) or because some relevant aspect of the labor relationship is private information (such as the ability of the employee).

A number of experimental studies in the context of organizations have been conducted to gain insights into the role of communication in mitigating adverse effects arising from coordination problems and information asymmetries. This paper provides a selective review of these studies especially relevant for organizations. It also focuses predominantly on studies that implement exante communication, which refers to communication that takes place before players decide on their actions.

The rest of this paper is organized as follows. In Section 2, studies are reviewed that focus on the effects of communication on coordination within organizations and on the interaction effects of communication and competition in these settings. Section 3 focuses on studies on moral-hazard problems that arise when managers have no direct control over the effort choices of their subordinates. Section 4 briefly outlines studies that analyze the interaction of communication with incentive schemes and the subsequent impact on employee motivation and counterproductive behavior. Section 5 briefly summarizes the findings from the literature and concludes. 


\section{Coordination and Competition}

Organizational success depends on the (often) independent decisions and actions of a group of actors. In particular, the achievement of organizational goals may require managers and employees to coordinate their actions in a particular way. Such coordination problems are often complex tasks. For instance, companies with multiple divisions might need to integrate and coordinate decisions made at different levels (e.g., production planning, distribution, marketing). Firms might have several production plants making semi-finished products that need to be assembled into final products. Manufacturing choices at these plants need to be coordinated, because the production of the final good depends on the efforts of each separate plant.

Often coordination problems have a weakest-link feature where a group's outcome is determined by the lowest level of any member's input. A classic example of a weakest-link problem, involves the manufacturing of products that require different production steps and where the overall quality of the product depends on the quality of any single item. Also, multinational organizations tend to have multi-tiered global supply chains, including sellers, partners, subcontractors and sponsors, which are all linked together in complex networks, where a problem in one area can easily have damaging effects up and down the chain.

Many experimental studies reviewed in this paper use the weakest-link game, which is also known as 'weak-link game' and 'minimum effort game', to capture these aspects and illustrate the problems that may arise when the members of an organization fail to coordinate their actions (for the seminal experimental paper, see Van Huyck et al., 1990, and for a recent contribution, see Riedl et al., 2016). In the weakest-link game, two or more players have to choose among several actions, often coined as effort levels. It has multiple Nash equilibria in pure strategies that can be Pareto-ranked. The highest Pareto-ranked equilibrium is payoff-dominant, generating the largest joint surplus, and requires that each player chooses the highest effort. Choosing high effort, however, entails some risk, because the player who chooses high effort levels is harmed if anyone else chooses a low effort level. Thus, low effort can be considered as a safe (equilibrium) choice in this game, which is inefficient. A main question addressed in the papers that are reviewed in the following is whether communication can help overcoming this low efficiency trap.

\subsection{Coordination with aligned incentives}

The effects of costless communication in coordination games have been widely studied in experimental economics and many studies have shown that cheap talk can be effective at resolving coordination failure and inefficient coordination (see for instance the studies cited in the introduction). For example, Blume and Ortmann (2007) study whether communication can help to coordinate on the efficient outcome in the minimum and median effort games. The median effort game is structurally similar to the minimum effort game, except that the group outcome is determined by the median effort level, rather than the minimum, chosen in the group. In both games, subjects in groups of nine choose among seven effort levels in eight rounds. In both the median and the minimum effort games, the most efficient outcome requires subjects to choose the highest effort level.

The authors compare treatments with and without pre-play communication, where in the former the members of a group can send each other a message regarding the intended effort level, before they make the effort choice. The results show that the efficient equilibrium is chosen significantly more often in the median and the minimum effort games with communication than in the same games without communication, suggesting that costless cheap-talk messages help overcome problems of strategic uncertainty, equilibrium selection, and coordination failure. 
Brandts and Cooper (2007) are among the first to study coordination in an organizational frame. They introduce a "corporate turnaround game" where a manager interacts with four employees. The employees play a weakest-link game, where each employee simultaneously has to choose a costly effort level and mutual gains may only be obtained if everyone exerts high effort. From a rational and selfish perspective, to be willing to choose a higher effort level, each employee must believe that the others will also choose a higher effort level. Therefore, the manager's task is to find a way to affect employees' beliefs about each other's actions.

The authors study the role of communication in this setting in three treatments: No Communication, One-Way Communication and Two-Way Communication. In all treatments subjects play thirty rounds of the turnaround game in fixed groups of five. In the first ten rounds of the experiment, the manager simply observes what employees do. The rationale behind this first set of ten rounds is to let players experience coordination failure prior to the managerial interventions, to be able to explore whether managers can overcome a history of coordination failure. In the remaining twenty rounds, the manager chooses a bonus rate for the employees in each round, which determines how much additional pay each employee receives per unit increase in the minimum effort. The employees observe the bonus rate and then select effort levels.

In the No Communication treatment, the manager can only use monetary incentives by choosing the bonus rate. In One-Way Communication, the manager chooses the bonus rate and at the same time can send a free-form cheap talk message to the employees. All the employees see the bonus rate and the message before choosing their effort levels. Two-Way Communication differs from the previous treatment in that employees can send a message back to the manager when they choose their effort level. In this case, messages are only received by the manager, but not the other employees. Treatment comparisons allow the authors to explore how effective communication in combination with financial incentives is at fostering coordination compared to financial incentives alone, as well as if the communication channel (one- versus two-way communication) matters for effort provision.

In all three treatments, Brandts and Cooper (2007) find that without communication and bonus payments (during the first ten rounds of the game) coordination on high effort almost never occurs. In the remaining 20 rounds, effort levels remain low in the bonus payment treatment without communication. In contrast, in both the one- and two-way communication treatments, higher minimum effort and higher payoffs are observed. The authors conclude that a manager's communication strategy has a larger impact on effort than the choice of a bonus rate. Moreover, two-way communication between the manager and the employees works better than one-way communication. A detailed analysis of the content of the messages sent reveals that the most effective managers' messages are those that request a specific effort level, emphasize the mutual benefits of high effort and the bonus rate chosen.

Kriss et al. (2016) investigate the role of communication in solving coordination problems in a weakest-link game, addressing the issue of costly and voluntary communication. They compare four treatments along two dimensions. They vary, first, whether communication is voluntary or mandatory and, second, whether and how much employees have to pay for each message they send. In all treatments, fixed groups of nine subjects in the role of employees interact for eight periods. In the Mandatory Communication treatment (MANDCOM), all subjects have to send a message at no cost before choosing their effort level. Messages can only contain a number corresponding to a level of effort in the game. In order to study whether participants would choose to communicate and what would be the effect of communication on coordination in this case, in the Voluntary Communication with Full Subsidy treatment (FULLSUBSIDY) subjects can-but do not have to- 
send a message. If they do send a message, this is at no cost. The Voluntary Communication with No Subsidy treatment (NoSubsidy) is the same as the one just described, except that employees have to pay a small fee when sending a message. Lastly, in the Voluntary Communication with a Partial Subsidy treatment (PARTIALSUbSiDy), employees also have to bear a cost when they send a message but this is lower than in NOSUBSIDY. Comparing the last two treatments to NoSuBSIDY allows for identification of whether the use of messages is affected when employees have to incur at least some communication costs, and whether this in turn affects how successful employees are at coordinating on high effort levels.

In this study the average effort and the minimum effort are highest when communication is mandatory and for free (MANDCOM). If communication is voluntary and for free (FULLSUBSIDY) almost all employees send a message, which results in similar effort levels and payoffs as in MANDCom. When sending a message entails a cost, the modal behavior is not to send a message. Even the very small cost in PARTIALSUBSIDY substantially decreases the use of messages relative to when communication is free. Importantly, participants to respond to incentives as messages are sent more persistently over time when communication costs are low than when they are high. The lesser use of communication has an adverse effect on the minimum effort. In No SUBSIDY it quickly approaches the lowest possible level, whereas it is higher in PARTialSubsidy but still lower than when communication is free. The results of this study strongly suggest that in order to facilitate coordination on higher effort equilibria in work teams, firms need to keep employees' communication costs low as otherwise communication does not take place, preventing its potentially positive effect to take roots.

Studying coordination problems that arise from a change in the composition of a group, Fehr (2017) investigates the effect of endogenous communication and whether subjects realize that communication may be helpful when experiences differ. The author implements three treatments which differ in whether communication is endogenous (ENDCOM), exogenously imposed (ExCom) or absent (BASE). The experiment consists of two parts. In Part I, which is common to all treatments, twelve subjects are randomly assigned to four groups of three and play 10 rounds of a weakest-link game. At the end of this part, the four groups are ranked according to their minimum effort in the $10^{\text {th }}$ round and matched such that a group of rank $r \in\{1,2\}$ is combined with a group of rank $r+2$. Thus, in Part II, two new groups of size 6 are formed. In each of these two groups, subjects are informed about the minimum effort the new members had chosen in the last round of Part I (i.e., group $r$ learns the minimum effort chosen by group $r+2$ in the $10^{\text {th }}$ round of Part I, and vice versa). Before the first round in Part II (round 11), subjects in ENDCoM vote on whether to implement a pre-play communication stage that would allow them to send a message before the effort decision in each of the remaining ten periods at a small cost. The message corresponds to an effort level of the weakest-link game, as in Kriss et al. (2016), The voting procedure is such that in each group one subject is randomly chosen and her decision is implemented for the whole group. The communication cost, however, has to be paid in each period by all subjects in a group where communication is available, irrespective of voting behavior. Moreover, to test whether subjects in less successful groups in Part II would revise their voting decision, in five randomly chosen sessions of ENDCOM a third part is implemented. At the beginning of Part III, subjects have to vote again on communication and play the game for another five rounds in the same group. There is no voting taking place in ExCOM and BASE.

The results show that individual effort, minimum effort and payoffs in treatment ExCom are substantially higher than in BASE, where there is no communication. In contrast, there is no significant difference in outcomes between a setting with exogenously implemented communication 
and a setting where subjects have the option to vote for the use of communication. This suggests that communication is effective at improving coordination irrespective of whether it is endogenously chosen or exogenously imposed. Focusing on the treatment with endogenous communication, Fehr (2017) notes, however, that only half of the subjects vote for communication and that subjects who experience miscoordination or inefficient coordination in Part I are those who mostly vote in favor of implementing communication. In ENDCOM, subjects who are in groups with communication choose higher effort levels, leading to higher minimum effort and higher payoffs, than subjects who are in groups where communication has not been implemented. Moreover, when given the chance to vote again in Part III, subjects who voted against communication in Part II do not revise their initial voting decision and continue to coordinate on the inefficient equilibrium. The author interprets the latter result as suggesting that subjects who experience inefficient coordination or coordination failure do not consider communication as a device to improve coordination and are therefore not willing to incur the (small) implementation cost.

A study by Brandts and Cooper (2018) focuses on the impact of the organizational structure on coordination and compares the performance of centralized and decentralized organizational forms by means of the "decentralization game". This is a coordination game played by a central manager and two divisions. Under centralization, the central manager assigns product types to each division, while under decentralization, division managers choose their own product types. The profit of each division depends on local tastes, a randomly determined state of the world, and the product types. The manager's profit is given by the sum of the divisions' profits. The central manager knows the probability distribution over states, whereas the divisions know the actual state of world. The game is constructed in such way that both, coordination over divisions' product choices and taking advantage of divisions' private information are necessary to maximize total surplus. Under centralization, the only equilibria are babbling equilibria in which the divisions' reports reveal no useful information to the central manager and the central manager chooses the same product type for both divisions. Centralization is predicted to achieve coordination but not efficiency. Under decentralization, efficient coordination (i.e., maximization of total profits) requires that divisions coordinate on different product types, depending on the state of the world. This makes efficient coordination a relatively complex task.

In all treatments, fixed groups of three subjects play the decentralization game for 18 periods. In the two Baseline treatments with decentralization and centralization (BASEDEC and BASECEN), manager and divisions cannot communicate, apart from reports about the state of the world that divisions make for the manager. In other treatments the authors study the effect of different forms of communication. In a treatment called Division Suggestions (DIVSUG), divisions send messages about which products to choose before decisions are made. In treatment Manager Suggestions (MAnSug), before divisions choose their product types, the central manager sends a menu of suggestions about what product types to choose for each state of the world. In both these treatments messages are pre-determined and the divisions choose their own product types. In two other treatments, communication features free-form chats. In Chat-Decentralization (CHATDEC), the two divisions can talk freely prior to choosing product types. In Chat-Centralization (CHATCEN), the central manager and two divisions can talk freely before the central manager chooses product types for the divisions.

The results of this study can be summarized as follows. In the Baseline treatments, centralization leads to more efficient coordination than decentralization because in the latter divisions fail to coordinate their product types. Allowing for limited communication in the form of manager or division suggestions does not improve the efficiency of coordination relative to the Baseline treatments. In both DivSug and MANSug, decentralization results in persistent miscoordination or 
inefficient coordination. In stark contrast, free-form chats appear to help solving the coordination problem under decentralization. Performance in ChatDec is similar to performance in BASECen, because divisions tend to coordinate on the safe equilibrium. Total surplus in CHATCEN is significantly higher than in both CHATDEC and the BASECEN. The reason for the better performance of free-form chat when decision making is centralized lies in the fact that the efficient outcome is chosen much more frequently than in the other treatments. This efficient coordination is mostly due to the fact that divisions tend to reveal truthful information and rarely lie about the state of the world.

\subsection{Coordination with negative externalities}

The studies surveyed so far show that communication has a great potential to enhance efficiency in organizational coordination problems. A common denominator of these studies is that incentives of agents are aligned and that enhanced coordination creates better outcomes for everyone. However, in some situations better coordination may not always imply higher overall efficiency. For instance, when coordinated actions of some agents cause negative externalities on other agents, the overall effect on group surplus might in fact be detrimental. In the following, the focus is on studies that have analyzed the interaction of communication and coordination in this kind of settings.

Sutter and Strassmair (2009) focus on the contrasting effects that communication may have in settings where teams compete with each other. On the one hand, allowing for communication might induce within-team cooperation, which would increase organizational performance. On the other hand, it might also facilitate between-teams collusion on low effort, which would be detrimental for the overall performance of the organization.

The authors implement a game where groups of six workers are split in two teams which compete for a prize. In each team, workers individually and independently choose an effort level, which contributes to the production of the team's output. The team with the higher output wins the tournament. The tournament is repeated for ten rounds, during which teams are kept fixed and the same two teams compete with each other.

The main treatment variables are whether members of a team can communicate only with each other, or can also send messages to the competing team. The treatment NoComm serves as control and does not permit communication. In INTRA, members of a team can communicate only within their own team. In INTER, competing teams can communicate with each other, but within-team communication is not possible. In the treatment INTRA+INTER, all messages are public for all members of the two competing teams. In an additional treatment, ENDO, subjects can choose whether to communicate only with their own team members or whether messages can be sent also to the competing team. The endogenous treatment is implemented to check for subjects' preferences for explicit collusion.

The results of this study show that in all treatments where communication within teams is possible (INTRA, InTRA+INTER and ENDO) effort levels are significantly higher and more homogeneous than in the treatment without communication. Allowing for between-teams communication lowers effort to levels close to those observed in the treatment without communication. In most cases, team members use the within-team messages to try to coordinate on identical effort levels, which increases effort levels. When between-teams messages are allowed, teams try to collude by agreeing on taking turns in winning, which pushes efforts down. These results indicate that communication within teams facilitates coordination and proves to be an efficient means to increase cooperation and reduce the free-riding within a team. However, communication between teams can lead to collusion and to significantly lower efforts and organizational performance. 
Cason et al. $(2012,2017)$ also explore the potentially harmful effects of (within-group) communication by means of competitive coordination games. Competitive coordination games capture those situations, frequent in organizations, where teams compete against each other and where a team's success in coordinating within-group efforts often determines the outcome of the between-group competition. To study such contexts, the authors embedded a weakest-link game in a competitive rent-seeking contest. In the weakest-link game, subjects in groups of three make their effort choices simultaneously, knowing that the higher the effort level they choose the higher is the chance their group would win a prize against another randomly paired group. Groups play this stage game for 30 periods. A key feature of this framework is that while, ceteris paribus, coordination on higher efforts increases the probability of winning the prize, and therefore the expected payoff of that group, it also reduces the expected payoff of the competing group. Hence, in this setting higher effort is socially wasteful because, due to the negative externality imposed on the competing group, efficiency decreases with higher effort and increases when players of both groups manage to coordinate on lower effort levels. This is the main difference with the aforementioned study by Sutter and Strassmair (2009), where higher efforts increase payoffs. Another difference is that a team's effort is determined by a weakest-link game instead of an additive effort game. Moreover, in Cason et al. $(2012,2017)$ the prize is rewarded according to a probabilistic contest success function rather than deterministically awarded to the group with the higher effort.

To explore whether intra-group communication can damage efficiency and decrease social welfare, Cason et al. (2012) implement six different treatments. In the baseline treatment (NoComm), subjects simply play the described game without being able to communicate with each other. In three group communication treatments, subjects can send free-form messages before making their effort choices. In treatment INTRA, subjects in both groups can send messages only to members of their own group (3-person chat). In treatment INTER, subjects in the two groups can communicate with each other, such that each message is seen by everyone in the two groups (6-person chat) and no private within-group messages are allowed. In treatment INTRA+INTER, subjects can send messages both in the 3- and in the 6-person chats, where in the former case, only own group members can see the messages and in the latter, messages are observable by everyone in both groups. In two additional treatments the two groups are replaced with two individual players who compete for a prize. From an organizational perspective the latter treatments are less interesting and are not discussed further here.

The authors find that intra-group communication leads to significantly greater within-group coordination and higher efforts than in a setting where communication is not allowed. Consequently, this kind of communication results in substantially lower overall payoffs and efficiency. On the other hand, allowing inter-group communication, besides improving within-group coordination, reduces competition between groups leading to significantly lower effort levels, higher payoffs and higher efficiency relative to the NoComm treatment. The highest level of efficiency is reached when both types of communication are allowed (INTRA+INTER). In this case, subjects coordinate on low effort levels which yields high payoffs.

Cason et al. (2017) build on the former study to further investigate conditions under which communication may have detrimental effects on efficiency. In particular, they study the impact of asymmetric and endogenous communication on within-group coordination and on between-group competition in four treatments. In three treatments the communication channel is exogenously varied to assess the effect of symmetric and asymmetric communication in the competitive coordination game. In the control treatment (NC-NC), subjects cannot communicate, while in the $\mathrm{C}-\mathrm{C}$ treatment members of both groups are allowed to communicate with members of their own 
group. In the novel treatment $\mathrm{C}-\mathrm{NC}$, members of only one of the two groups can communicate with members of their own group before their effort decision. In all communication treatments communication between groups is not permitted. To study whether the effects of communication persist when groups can choose whether to communicate and whether groups actually choose to communicate even though communication may harm efficiency, the authors implement an endogenous communication treatment according to the following procedure. After ten rounds of the NC-NC treatment, three players in each group vote on whether to establish communication for the successive ten rounds. Subjects vote twice: first, before round 11 on (not) to have communication in rounds 11-20 and, second, before round 21 on (not) to have communication in rounds 21-30. In both cases, subjects in a group have to reach unanimity.

The results of this study show that when communication is asymmetric (treatment C-NC), the communicating and the non-communicating group behave quite differently. Specifically, the non-communicating group in $\mathrm{C}-\mathrm{NC}$ achieves similar coordination as the non-communicating group in NC-NC and earns similar payoffs to the communicating group in the C-C treatment and lower payoffs than the non-communicating groups in the NC-NC treatment. In contrast, the communicating group in $\mathrm{C}-\mathrm{NC}$ achieves better coordination and earns higher payoffs than the communicating group in the $\mathrm{C}-\mathrm{C}$ treatment and similar payoffs to the non-communicating group in the NC-NC treatment. In sum, within-group communication leads to more aggressive competition. (i.e., higher efforts) which leads to lower payoffs and efficiency than in the absence of this kind of communication. This effect is strongest when within-group communication is possible in both groups. The authors conclude that asymmetric communication has a less strong negative impact on payoffs and efficiency than symmetric communication, but it still leads to lower efficiency relative to a setting where communication is not allowed at all.

For the endogenous communication treatment, Cason et al. (2017) find that most groups choose to communicate even though communication lowers efficiency. However, the authors find no differences in effort, coordination and payoffs between the endogenous and the exogenous treatments, which suggests that what affects behavior is the type of communication channel, and not whether such a channel is chosen endogenously or imposed exogenously.

\subsection{Overview}

Experiments on coordination games with communication have identified some broad regularities which are briefly summarize here. First, costless pre-play communication can be effective at resolving coordination failure and inefficient coordination in organizational settings, even when it is only one-way. Second, cheap talk works in both cases when messages are pre-determined and when they are unrestricted. Third, communication helps reaching efficient coordination outcomes independent of whether it is exogenously imposed or endogenously chosen. Fourth, in the latter case, the choice of sending a message strongly depends on whether it is costly to do so and on how costly it is, as the frequency of communication tends to decrease with its cost. Fifth, there may also be a dark side of communication. Some of the reviewed studies show that communication may be harmful for organizations when coordination among workers is associated with negative external effects and has therefore the potential to be detrimental in terms of efficiency. Specifically, communication within teams may make them behaving more aggressively in tournaments and communication between teams can lead to collusion, which both may lower organizational performance. 


\section{Asymmetric Information}

An inherent feature of many labor relationships is that information is distributed in an asymmetric way between the employer and the employee. In the following, the focus is mostly on cases where the employee has an information advantage over the employer, because the majority of the experimental studies that have been conducted so far in this context refer to these cases. In this context, a central distinction has to be made between "hidden action" and "hidden information" problems (Bolton and Dewatripont, 2005). Hidden action (or moral hazard) problems emerge when the employer is not able to observe the employee's actions. A classical example concerns a principal-agent problem where the employer (principal) can observe the output produced but cannot monitor or verify the effort the employee (agent) has invested to produce this output. In these situations, the employee may have an incentive to choose actions that are favorable to herself but harm the employer (for instance, exerting inefficiently low effort). On the contrary, hidden information (or adverse selection) problems occur when the employee's ability or productivity are not verifiable for the employer, in which case employees may have the incentive to conceal their true ability.

\subsection{Hidden action problems}

A number of articles have investigated the role of communication in moral hazard settings. Charness and Dufwenberg (2006) modify the classical "trust game" (Berg et al., 1995) to include hidden action. In their game, the first mover represents the principal (or employer) and the second mover the agent (or employee). The first mover has to choose between trusting and not trusting the second mover (choosing action "In" and "Out", respectively). The interpretation is that by choosing "In" the principal can offer an incomplete labor contract with the potential to accrue gains from trade. If the principal offers a contract (i.e., trusts), the agent can choose between a non-trustworthy action ("Don't roll") and a trustworthy action ("Roll"). After "Roll", the outcome for the principal is stochastically determined: with a probability of $5 / 6(1 / 6)$ the favorable (unfavorable) outcome is realized. In this game, given that the principal trusts, profit-maximization requires that the agent does not honor trust. A forward looking principal anticipates this and therefore does not trust in the first place. In several experimental treatments, the authors vary a) the size of the outside options for the players in case the principal does not trust and b) whether one player is allowed to send free-form messages to the other player.

The authors find that one-way free-form communication from the agent to the principal has a significant positive effect on the levels of trust, trustworthiness and, consequently, the realized efficiency of the transactions. In contrast, allowing for one-way communication from the principal to the agent does not change behavior relative to a control treatment without messages. In order to test the link between players' beliefs and choices and the interaction with communication, the authors elicit both the first-order beliefs of the principals (i.e., the expected proportion of second movers who choose "Roll") and the second-order beliefs of agents (i.e., their expectations about the average beliefs by the principal). Using this information the authors find that the interpretation of the content of the messages plays an important role for decisions. Specifically, messages sent by the agents that can be categorized as promises to take the trustworthy action are associated with significantly higher trust, trustworthiness and realized efficiency as compared to messages that do not involve a promise.

In a variation of the described experiment, Charness and Dufwenberg (2010) conduct an additional treatment in which, contrary to the original setup in Charness and Dufwenberg (2006), 
agents cannot send free-form messages, but can only choose between making a "bare promise" (sending a pre-formulated message that the agent intends to choose "Roll") and sending no message. In this treatment, the large majority of agents send a promise. However, while the share of agents who behave in a trustworthy manner increases somewhat relative to the control condition without communication, the share of principals who trust the agent does not increase. Hence, taking together the results from both studies, it appears that in the investigated setting free-form communication is more effective in enhancing trust and efficiency than (pre-formulated) reduced form messages including promises.

Building on the experimental setup introduced by Charness and Dufwenberg (2006), Hoppe and Schmitz (2018) analyze a situation in which principals and agents bargain over labor contracts in an alternating offer protocol. When a contract is concluded, agents' chosen effort can be either high or low which in turn affects the principal's payoff. Similar to Charness and Dufwenberg (2006), if a low effort is chosen, the payoff for the principal is low with certainty (bad outcome). If the agent chooses high effort, the principal's payoff is high with a high probability (5/6 - good outcome), but the bad outcome can still be realized (with probability 1/6). The possible parameters that can enter the contract between principal and agents (wages or effort levels) depends on the specific treatments, as described below.

The authors implement eight treatment variations which vary the verifiability and observability of agents' efforts as well as whether or not principals and agents can communicate by sending messages to each other both before and during the negotiation. In a first set of four treatments, the outcome is contractible; that is, the output of the agent can be observed by both players, and wages can be made contingent on the realized output. The second set of treatments adds private information on the side of the principal to each condition, such that only the principal will be informed which outcome has materialized, implying that contracts cannot condition wages on the output.

Hoppe and Schmitz (2018) find a significant positive effect of communication when effort is not observable (i.e., hidden action). In these treatments, expected total surplus for principals and agents is increased with communication. On the other hand, when effort is verifiable and contracts can specify the effort level to be provided by the agent, communication does not significantly change the expected total surplus. The authors also analyze the communication content which allows them to provide some more insights into the mechanisms that might drive the positive effect of communication. Specifically, when outcome is contractible and effort hidden, communication allows the principal to explain the agent that-given an incentive-compatible contract was agreed upon - it is optimal to exert high effort, which reduces strategic uncertainty. This would explain why in the treatments where effort is verifiable - thus, no strategic uncertainty-communication has no effect. Moreover, in the case with information asymmetries on both sides, where effort is unobservable and the output is not contractible, communication is associated with higher wage offers and more frequent choices of high efforts. In this case, the content analysis reveals that when agents chose high effort levels often a promise was made, whereas in the cases with low effort levels this was not the case. This result is similar to the observations in the study by Charness and Dufwenberg (2006), and is consistent with guilt aversion on the side of the agents.

An important workhorse to explore employer-employee relationships that involve moral hazard is the "gift-exchange game". In this game, the employer sets a (non performance-contingent) wage for the employee who in the next step decides on the effort level. Effort is costly for the worker, but generates revenues for the employer. In the standard gift-exchange setting a profitmaximizing employee would exert minimum effort at each given wage level and, anticipating this, 
profit-maximizing employers would offer the lowest possible wage. Yet, starting with the seminal study by Fehr et al. (1993), it has been shown that, typically, employers pay higher than minimum wages, employees choose higher than minimum effort and there is a significant positive relationship between wages offered and efforts chosen. Numerous replications of this experiment have shown the robustness of these results in many different circumstances (see Charness and Kuhn, 2011, and Casoria and Riedl, 2013, for surveys of the literature on gift-exchange experiments).

Several studies have investigated how communication interacts with gift-exchange. Cooper and Lightle (2013) conduct two experiments on variants of the gift-exchange game. In the first experiment, they introduce one-sided communication from the employee to the employer. Here, the central question is whether communication is used by employees as a substitute for costly effort to reciprocate to the wage choice of the employer, or, alternatively, as a means to foster the employers' learning about the positive wage-effort relationship that the latter can utilize in later rounds of the game. When communication is possible, employees can send a free-form message to the employer after being informed about the wage offer but before choosing their efforts. If a message is sent, the employer observes this message together with the employee's effort level. The experiment is implemented in a strangers design where employers and workers are rematched with different partners in each of the 20 periods. Two treatments are implemented which differ in when employee messages are available. In the Messages First treatment, messages are available only in the first 10 rounds and in the Messages Second messages are available only in the last 10 rounds.

Results show that the introduction of messages significantly increases wage offers and effort levels in both treatments, due to employees' reciprocity. Moreover, messages have a lasting effect in the Messages First treatment, because even after the possibility of sending messages has been removed, wages, effort and profits of employer and employees remain at a high level. Importantly, the data show that, communication does not alter the wage-effort relationship. This rejects the hypothesis that communication and effort are substitutes and supports the alternative hypothesis that communication fosters employers' learning about the profitability of gift-exchange. A content analysis of messages supports this interpretation. Messages that express positive or negative sentiments against the employer do not affect wages in future rounds. In contrast, messages that contain an advice for the employer and explain that higher wages lead to higher effort are associated with higher wages in subsequent rounds.

The second experiment is conducted to provide further evidence for the notion that messages lead to higher wages by helping employers to learn about the positive relationship between wages and effort. In this experiment, employers are exogenously provided with information about this relationship. In particular, in the first 10 out of 20 experimental rounds, employers receive feedback on the wage, effort and payoffs of one employer-employee pair randomly drawn from the same round in a previous session without communication. The authors find that feedback also has a positive impact on wages here, but the effect is smaller than with the possibility to communicate. According to the authors, this might be related to the fact that the feedback given is noisier than messages and provides less guidance to employers concerning the wage to choose.

Bolton and Werner (2016) implement a gift-exchange experiment in which one department head interacts with two employees that are heterogeneous regarding their productivity (i.e., their efforts affect the department head's profits differently). While the main focus of the study is on the employees' responses to wage differences, two treatments investigate how communication influences gift-exchange. In these treatments, department heads can send a text message to both employees together with their wage offers. When wage differences are transparent, communication may have 
a strategic value for the department head. For instance, it could be used to explain the wage difference in order to avoid negative reactions by those workers who receive a lower wage.

In this study, communication is found to have a significant effect on behavior of both department heads and employees. First, wage offers in the treatments where communication is possible tend to be larger than in the treatment without communication and this difference is particularly pronounced for offers to high productivity employees. Moreover, controlling for wage offers, certain types of messages are significantly correlated with effort levels, but their effectiveness depends on the employee type. Appealing to fairness and emphasizing efficiency gains is associated with increased efforts by high productivity employees, while justifications of inferior payments have a positive impact on efforts of low productivity employees. These observations suggest that the effectiveness of communication may depend on specific characteristics of the interaction partners, like productivity.

In the one-shot gift-exchange setting by Issgin (2017) firms differ in the marginal return for each unit of workers' effort. In a competitive market setting with excess supply of workers, firms make wage offers to workers and - upon being hired - workers choose their effort levels. Two treatments differ in whether a firm's productivity type is public information (i.e., the worker receives this information together with the wage offer) or remains private information of the firm. Two other treatments vary whether or not free-form chat messages can be sent to all participants in the experimental session. The author finds that, without communication, public information does not change average wages and effort as compared to a setting with private information. However, giving the possibility to communicate has a strong positive effect on wage and effort levels, irrespective of whether productivity differences are transparent or not.

Ben-Ner and Putterman (2009) utilize the trust game (Berg et al., 1995) to explore the role of contracts between employer and employee in the presence of moral hazard and how it interacts with communication. In this experiment, first and second movers can communicate either via messages containing numerical information (proposals and counter-proposals on the amounts to be sent and returned) or via free-form chat. In addition, participants have the possibility to enter contracts that lead to binding choices, conditional on the consent of both interaction partners. Communication increases efficiency in this setting. In particular, the highest levels of trust and trustworthiness are achieved in the interaction that integrates free-form chat. Furthermore, when contracts can be written, more than $70 \%$ of the interacting partners refuses these contracts and relies solely on trust.

Charness et al. (2013) investigate whether the contracting procedure between firm and workers affects gift-exchange between the two parties and find support for this conjecture. These authors implement a version of the gift-exchange game that consists of three stages. In the first stage, one party offers a contract to the other party. In the second stage, the receiver of the offer either accepts or rejects it. Upon acceptance, in the third stage the worker chooses an effort level which is costly to the worker and generates profits for the firm. The authors conduct four treatments that vary a) whether the firm or the worker proposes the contract, and b) whether the contract proposal specifies only the binding wage level or also a non-binding effort level. Since the effort level is non-binding, it is considered cheap talk from a theoretical perspective.

A main result of this study is that the contractual procedure matters for the final outcome. When workers propose the contract and the contract also includes an effort level, the effort exerted is significantly higher than in all other conditions. In particular, effort promises by the worker increase actual effort relative to the treatments where no cheap-talk is possible (i.e., when the contract only specifies the wage). In contrast, effort requests by the firm do not have an effect on 
effort choices. Moreover, the share of workers who provide effort of at least the level suggested in the contract is significantly higher in the treatment where workers propose the effort level. This findings indicate that workers have an inclination to live up to their effort promises.

Testing for patterns of gift-exchange in the field, Davies and Fafchamps (2017) focus on the use and effectiveness of promises and feedback in labor relationships in Ghana. In this experiment, students and entrepreneurs from Ghana were recruited as participants. Students were in the role of workers, whereas entrepreneurs were recruited for the role of employers. The authors implement a modified version of the gift-exchange game where, depending on the treatment, the workers can make a promise to the employers about future effort choices and the employers can send either positive or negative feedback to the workers after effort has been chosen. The game is repeated and each period of the game consists of three stages. In the contracting stage, the employer can choose to make an offer to the worker, who can then either accept or reject it. Upon acceptance, in the second stage, the worker receives a wage and chooses either a low or a high effort level. In the final stage, the employer is asked what wage she would offer if the worker chose low effort and what she would do if the worker chose high effort. The worker is asked for the minimum payment at which they would accept the offer. If the offer and the desired minimum payment are consistent, the worker and the employer will contract again with each other in the next period, skipping the first stage. If there is no match, contracting in the next period will happen as before.

Four treatments are implemented. In treatments $1 \mathrm{E}$ and $1 \mathrm{C}$, workers and employees cannot communicate. In the former of these two treatments workers can choose between providing high and low effort, while in the latter workers can only choose the high effort. The comparison between these two treatments permits to assess the effects of not having fully enforceable contracts. Two treatments are run to investigate the role of communication. In treatment 1EM, the employer can choose between no feedback, three positive and three negative feedback messages to send to the worker after the effort choice. In treatment 1EMP, in addition, the worker can make a predefined promise for the next period stating: "If you offer me a high payment, I will choose high effort." Subjects participate in all four treatments and are rematched after each treatment.

In accordance with most of the gift-exchange literature, Davies and Fafchamps (2017) find positive reciprocity in all treatments, i.e., effort is higher in response to higher wages. Introducing the possibility of giving feedback has no effect on wage offers, but it significantly increases workers' reciprocity at high wages. They choose high effort more frequently compared to the no-feedback treatments. However, workers' promises (in addition to employers' feedback) do not have a significant impact on wage offers, effort choices or the wage-effort relationship. Taken together, these results suggest that the effectiveness of communication in the setting under study depends on the wage that is offered and that worker promises on top of employer feedback has no additional effect.

\subsection{Hidden information problems}

The role of communication in settings with hidden information has been examined in a couple of studies. First, Charness and Dufwenberg (2011) focus on the hidden information problem that emerges when agents differ in their abilities that cannot be observed and verified by the principal. In this case, low-ability agents have an incentive to conceal their true type. In the implemented setting, agents can be either of high or of low ability and there are two types of jobs, one that requires high ability and one that requires low ability.

To investigate the role of communication, Charness and Dufwenberg (2011) implement a $3 \times 2$ design, where three conditions that differ in the surplus created by the participation of the lowability agent are interacted with whether or not communication is possible. In one treatment, if a 
contract is offered by the principal and the agent chooses the low-ability job, the surplus generated is higher for both principal and agent compared to the case when no contract is offered at all. Hence, the participation of the low-ability agent is Pareto-improving over the no contract situation. However, rational agents would choose the high-ability job after receiving a contract, irrespective of their true ability, and the principal's best response is not to offer a contract. In the other two treatments that vary the payoff structure, behavioral predictions for rational principals and agents do not change, but participation of the low-ability agent does not lead to a Pareto-improvement. In the communication treatment variation, in one case the agent can send a free-form message to the principal after being informed about the type and before the principal decides whether or not to offer a contract, whereas in the second case such communication is impossible.

In the treatment where participation of low-ability agents is Pareto-improving, communication is found to be effective at mitigating the hidden information problem. The share of low-ability agents who choose the low-ability job after being offered a contract is almost twice as high when communication is possible than when it is not. The share of principals who offer a contract also increases, but not significantly so compared to the no-communication setting. Moreover, the analysis of the communication content reveals that a large share of low-ability agents sends messages that reveal their true type and include promises to take the low-ability job. These promises almost always result in a job offer by the principal. In addition, if a contract is offered after such a message, the low-ability agents always keep their promise and choose the action they announced. In contrast, when low-ability agents participation cannot lead to a Pareto-improving outcome, communication has no positive effect. In this case, only a minority of low-ability agents chooses the low-ability job, irrespective of whether communication is allowed or not. Taken together, these results suggest that communication is effective in utilizing the potential contribution of the low-ability agents to the joint surplus.

Building on the framework of Charness and Dufwenberg (2011), Goeree and Zhang (2014) introduce competition among agents. Their aim is to study whether communication leads to efficient contracting also in the scenario where two agents compete for a single job. The authors use the one-shot hidden information game introduced above and implement treatments with and without communication, and with and without competition between agents. Goeree and Zhang (2014) also vary a third dimension, namely whether or not the principal's payoff resulting from the trustworthy action by the high-ability agent is uncertain. The authors find no significant differences between treatments with and without uncertain payoffs and consider only the pooled data.

In the no-competition treatments, one principal is paired with one agent. In the treatments with competition, each principal is paired with two agents and has to select one of the two before playing the hidden information game. In the communication treatments, both agents can send one-way free-form messages to the principal. Agents cannot observe each other's messages, which can be seen by the principal only.

The authors find that communication raises efficiency when there is no competition, thus confirming the findings of Charness and Dufwenberg (2011). In addition, they find that competition raises efficiency when there is no communication. However, efficiency decreases when competition is introduced in the setting where communication is available. By analyzing the content of the messages in the different treatments, Goeree and Zhang (2014) provide an explanation for this negative efficiency effect of communication: with competition fewer messages are sent that contain information about the ability of an agent, which makes it more difficult for the principal to select high-ability agents. In turn, principals become more cautious and hire an agent less often than in the absence of competition. Overall, the results of this study show that communication and 
competition can act as substitutes and highlight the fragility of communication as a means to increase efficiency.

\subsection{Overview}

In summary, the results from the studies reviewed in this section suggest that communication can help mitigate problems arising from information asymmetries between employer and employees. Several studies find that communication mitigates moral hazard and leads to more gift exchange. Moreover, although the literature is not entirely conclusive, it seems that free-form communication is more effective at reducing moral hazard than restricted and standardized communication. Only a couple of studies exist investigating the effect of communication in hidden information settings. These studies suggest that the effect of communication is context dependent. Specifically, when interactions between employer and employee are bilateral, communication significantly improves efficiency when participation of the employee is possible. Yet, if competition is introduced into this setting the effect of communication is reversed.

\section{Incentives}

The papers reviewed in this section focus on the interaction of communication with the monetary incentive scheme that the employee is exposed to. The first part of this section surveys papers that address the question of how communication interacts with different incentive schemes. The second part deals with papers that study whether adverse affects for the organization triggered by performance-based compensation schemes can be mitigated by communication. The final section, reviews selected studies examining the role of communication in diverse public good settings, which can be seen as describing teamwork, and are thus relevant to organizational settings.

\subsection{Monetary and non-monetary incentive schemes, communication and effort}

How do different incentive schemes respond to the introduction of communication? Harbring (2006) contributes to answering this question by comparing a team and a tournament incentive scheme under two communication channels. One channel is one-way and allows only for restricted messages whereas the other channel is two-way and allows for free-form messages. Participants are randomly matched in pairs and have to choose an effort level. In the team compensation scheme, the two agents are equally rewarded on the basis of their collective output. Under this incentive scheme, the Nash equilibrium predicts inefficiently low levels of effort. In the tournament incentive scheme, the two agents are rewarded according to the ranking of their outputs. The agent choosing the higher effort level receives a larger payoff (a winner prize) than the agent with the lower effort. Here, the unique Nash equilibrium predicts that both agents exert maximal effort. Importantly, however, agents can improve their joint payoff by coordinating on lower efforts.

In the study six treatments are implemented, all consisting of a total of 20 rounds. At the beginning of the experiment participants are informed that there are 10 rounds of interaction and that afterwards the experiment will continue in a manner not disclosed in advance. After the first 10 rounds, it is then announced that another 10 rounds with the same pair matching will be played. In two control treatments (TEAM and TOURN) no communication between agents is allowed. In two treatments (TEAMANN and TOURNANN), communication is restricted to announcing effort levels, i.e. one agent in each pair can announce the effort she intends to choose before both agents simultaneously decide on their effort. The opportunity to make an announcement alternates 
between agents so that each agent announces an effort level 10 times during the 20 rounds of interaction. Further, in two chat treatments (TEAmCHAT and TOURnCHAT) both players in a pair can simultaneously send unrestricted messages to each other throughout the experiment.

The results show that overall, under both incentive schemes, communication leads to more coordination than in settings without communication. More precisely, average effort and the percentage of maximal efforts are highest in TEAMCHAT and lowest in TOURNCHAT, while restricted communication leads to effort choices that lie between these two extremes. In the tournament setting, the opportunity to announce the effort choice facilitates collusion between subjects, so that they are able to alternate in winning the prize and obtain equal payoffs in the end. The chat instead helps to keep effort stable over time both in the team and in the tournament compensation schemes.

In another study, besides exploring the interaction effects of communication and monetary incentives, Kvaløy et al. (2015) investigate whether communication per se can increase the motivation of the workforce and lead to higher efforts. The authors conduct a field experiment in which they hire students, who are not aware of participating in an experiment, to enter data from official ice hockey game reports into a database. Subjects are randomly assigned to one of four treatments varying two dimensions: performance pay versus no performance pay and motivational talk versus no motivational talk. In the two treatments with motivational talk, subjects were exposed to simple motivational sentences meant to (potentially) enhance intrinsic motivation. In the two performance pay treatments, subjects received a small piece rate on top of the fixed payment for each game report they enter into the database.

The authors find that adding the motivational talk to pay for performance significantly increases the number of entered games. The authors note that motivational talk alone also has a positive but insignificant effect on the number of entered games, while performance pay alone has a significantly negative effect. The same results are found when analyzing the quality of work as performance pay alone leads on average to more mistakes per entered cell, but combining performance pay and motivational talk significantly decreases the number of mistakes. Motivational talk and monetary incentives, therefore, appear to be complements. Subjects respond to the motivational talk by increasing their performance only when they also receive a performance pay.

\subsection{Incentives and counterproductive behavior}

A couple of studies aim at understanding the role of communication in the context of counterproductive behavior when workers might choose actions that are detrimental for the employers or for other workers. The first study explores sabotage, i.e., employees who take actions to reduce the performance of their colleagues. The second study analyzes a setting in which employees have incentives to harm the employer.

Harbring and Irlenbusch (2011) use a laboratory experiment to study sabotage in repeated tournaments. In the experiment, one principal is matched with three agents and decides which tournament contract to offer. Such a contract rewards the agents with the highest output with the winner prize and the other two agents with lower loser prizes. A contract specifies the total wage sum and the wage spread, i.e., the difference between the winner prize and the loser prizes. The agents observe the contract and simultaneously choose effort, which increases own output, and sabotage, which reduces the output of the other agents.

In the Baseline treatment, the setting just described is implemented using neutral framing. In the CHAT treatment, the four players are allowed to communicate with each other during the whole game. In the Framing treatment, communication is not permitted and the setting is framed as 
an employment situation and where the agents' actions are called "effort" and "sabotage".

In all treatments, Harbring and Irlenbusch (2011) find that both effort and sabotage levels increase with the wage spread, with the increase in sabotage being stronger than the increase in effort. There is also evidence for positive reciprocity, as effort is higher for the high wage sum than for the low wage sum, while sabotage does not differ for different wage sums. The two treatments Framing and CHAT are implemented to analyze possible ways of curbing sabotage. The authors find that framing the situation as an employment context and explicitly using the term sabotage indeed significantly reduce sabotage. Importantly, introducing communication has an even stronger impact on behavior and leads to significantly higher effort and lower sabotage. In particular, it appears that communication reduces sabotage because principals and agents manage to coordinate on high fixed wages that yield high effort, low sabotage and higher joint payoffs.

Cardella and Depew (2018) use a real-effort task to investigate the presence of workers' ratchet effect. That is, the phenomenon that workers strategically restrict their current output, relative to their capability, because they anticipate that high levels of productivity will lead to increased expectations or lower pay in the future. In the experiment, workers complete a real-effort work task over two periods under a piece-rate incentive scheme. In particular, workers have to stuff and seal donor solicitation mailers in two working periods of 10 minutes each, with a 10 minutes break in-between. During this break, the experimenter counts the number of completed mailers for each participant and indicates on a sheet their total, their compensation for the first period, and their piece-rate for the second period.

In the BASELINE treatment, a fixed piece-rate scheme is used in both periods in order to identify the distribution of the true output capability of the participants and rule out strategic motivations to reduce output. In the three main experimental conditions, workers receive a reduced piecerate in the second work period if productivity is too high in the first work period, relative to an exogenously set productivity threshold. In the INDIVIDUAL treatment, workers' productivity is evaluated at the individual level. In the Group treatment, productivity is evaluated collectively for a group of seven workers. Finally, the GroupComm treatment is the same as Group, except that workers can communicate face-to-face before the task starts.

The authors find that workers significantly increase productivity in the second period of BASELINE. In INDIVIDUAL, workers significantly lower their output below the productivity threshold in the first period, consistent with the ratchet effect. In contrast, in GrouP, the first period output distribution is very similar to the one in BASELINE, so workers do not seem to restrict their output to avoid receiving a lower compensation in the second period. Specifically, without communication, workers in GRouP fail to coordinate on lower output and rather try to free-ride on the output restriction of others in the group. Importantly, allowing for pre-play communication among workers in GroupComm leads to a significant output restriction in the first period, providing evidence for the ratchet effect. This result indicates that communication facilitates coordination on output restrictions and may play an important role in the emergence of the ratchet effect in group compensation schemes.

\subsection{Communication in public good settings}

The incentive structure in public good games resembles teamwork situations with free-riding opportunities. Therefore, insights from the literature on the effect of communication in public good games can be informative for communication effects in organizational settings. Early on researchers have looked into whether communication can help to overcome free-riding tendencies. In their seminal study, Isaac and Walker (1988) explored between-group, within-group and sequencing comparisons 
on the effects of communication on contribution behavior in a voluntary contribution mechanism (VCM, also known as linear public good). The reference treatment was one where communication was not allowed. Communication was basically free-form with some restrictions depending on the treatment. The results showed that in any communication treatment contributions to the public good where higher than when communication was not allowed. Interestingly, when communication was allowed in the beginning but disallowed later, the positive effect remained indicating a positive spillover effect of communication.

In the aforementioned treatments all participants had the same endowments. Isaac and Walker (1988) also investigated how communication affects contribution behavior when endowments are asymmetric. Specifically, the authors compared treatments with symmetric and asymmetric endowment where communication was allowed in the first 10 periods but not allowed in the second 10 periods. With communication voluntary contributions where high with symmetric and asymmetric endowments, albeit contributions were somewhat lower in the latter case. When the possibility to communicate was removed contributions remained high with symmetric endowments but broke down completely with asymmetric endowments.

In another influential early paper on the topic, Ostrom et al. (1992) explored the effect of communication alone as well as in combination with a sanctioning mechanism in a common pool resource $(\mathrm{CPR})$ setting. In their one-shot communication treatment participants played a CPR for 10 periods without communication, after which they had the possibility to discuss the decision problem for 10 minutes followed by another up to 22 periods of the CPR without communication. In the repeated communication treatment participants also played a CPR for 10 periods without communication, but now followed by the possibility to discuss the decision problem after each subsequent period. In both cases communication had a positive impact on the net yield from the common pool. When the endowment was low the net yield increased from $34 \%$ without communication to $99 \%$ with repeated communication, and when the endowment was high the net yield increased from $21 \%$ without communication to $55 \%$ with one-shot communication and $73 \%$ with repeated communication. This clearly showed that communication is also beneficial in CPR environments. In addition, the authors also found that when communication is combined with a sanctioning mechanism the efficiency increasing effects of communication are reinforced.

Summarizing public good experiments up to 2002 in a meta-analysis, Zelmer (2003) reports that (cheap-talk) communication among participants significantly increased the mean contributions to the public good relative to the no communication case. In a more recent survey of a few post-2003 public goods experiments allowing for different forms of communication patters, Chaudhuri (2011) corroborates this finding. Bochet et al. (2006) allow for three different communication types - faceto-face, chat-room, numerical cheap talk - and find that the first two lead to significantly increased contributions, whereas the last one does not exhibit a discernible effect relative to a situation without communication. In a follow-up study, Bochet and Putterman (2009) explored (among other things) if adding promises to numerical cheap talk affects contribution behavior. They report that this is not case. However, when numerical cheap talk is combined with punishment or promises and punishment contributions to the public good increase relative to a no communication benchmark. In study related the aforementioned ones, Masclet et al. (2013) study if communication in the form or cheap-talk threats to punish non-cooperative behavior affects public good contributions. In their study the authors allow for peer-punishment as in Fehr and Gächter (2000) but add a preliminary Threat stage where players can announce a threat to punish by submitting a threat schedule conditional on the contributions of the other players. The results show that communication, in the form of cheap-talk threats, increases contributions. Interestingly, threats are generally much harsher than actually dealt out punishment. In another treatment where players are informed about 
threats afterwards and can also punish deviations from threats, threats and actual punishment are more aligned. The authors report that overall contributions, punishment and, consequently, welfare in the treatments with communication do not differ from a baseline treatment without threats.

Chaudhuri et al. (2006) studied the effect of communication in an intergenerational advice setting (Schotter, 2003). In this setting an earlier generation of participants who played the public good game can give advice to a later generation on how to play the game. This can be done privately from an individual player to another individual player, publicly where individual players of the later generation can see all individual advice of the earlier generation, and the advice can be made common knowledge by being read out aloud. The results show that only when advice is common knowledge it has a significantly positive effect on public good contributions. The authors attribute this effect to social learning which is more difficult or impossible when advice is private or public.

Oprea et al. (2014) analyze the role of free-form communication in discrete time and continuous time public good problems. They find little differences in contributions between the discrete time and continuous time setting when communication was not allowed. However, with freeform communication contributions increased in both settings, with an especially strong and robust increase when the game was in continuous time.

Only a few studies explore the role of communication for leadership in public goods settings. Pogrebna et al. (2011) and Dannenberg (2015) compare leading-by-example with leading-by-words in slightly different settings. The main difference between these studies is that in the former there is no pre-announced last period, whereas in the latter participants are informed about how long the game will take. Both studies compare the effect of a binding commitment of the leader (i.e., the leader is the first to contribute to the public good) and a non-binding announcement (i.e., the leader announces how much he or she plans to contribute) to an environment without communication and commitment. The results of the two studies regarding the role of communication are mixed. Pogrebna et al. (2011) find that both leading-by-example and leading-by-words increases contributions to the public good, whereas Dannenberg (2015) reports a positive effect only of leading-by-example. The latter author concludes that "when players are appointed to lead by example they tend to set good examples, arguably because that role comes with a certain kind of observability. In contrast, when subjects are appointed to lead by words, they pledge to contribute a large amount but the actually chosen contribution is much smaller." (p. 84).

\subsection{Overview}

Communication is found to be effective at increasing agents' performance under monetary incentive schemes. In particular, free-form communication appears to work better than restricted messages both at increasing effort and at improving coordination. Communication in the form of motivational talk has a positive effect on agents' performance when it is combined with monetary incentives. When given the chance to engage in sabotage and reduce a co-worker's performance, agents do so if they do not have the possibility to communicate with each other. Introducing communication, decreases sabotage, improves coordination between principal and agents and has a positive effect on agents' efforts. However, in a dynamic setting, by facilitating agents' coordination on low effort levels, communication leads to output restrictions and eases the emergence of the ratchet effect. In public good environments, that resemble teamwork settings, generally communication has positive effects, albeit some qualifications need to be put in place. It helps to overcome the free-rider problem in symmetric and asymmetric endowments, but the positive spillover effects of communication to environments without communication do not survive when 
endowments are unequal. Communication increases efficiency in common resource problems and this effect is enhanced when combined with a sanctioning institution. When communication is in the form of advice from one to another generation it only works when the advice is common knowledge. Communication significantly increases cooperation in continuous time public good games. However, adding communication in the form or punishment threats does not have a significant positive effect. Finally, the few studies investigating leading-by-words report mixed results relative to leading-by-example and settings without leadership.

\section{Summary}

In this paper, selected experimental papers have been reviewed that test the role of communication in organizational environments. These studies show that communication significantly and robustly affects decision-makers' behavior. Several main conclusions can be traced from this experimental literature.

With respect to coordination, communication is found to be generally effective in improving coordination in organizational settings. This is true both with restricted and unrestricted communication and regardless of whether or not communication is mandatory or optional. Importantly, when incentives of the decision-makers are aligned, communication improves payoffs and efficiency. However, communication can also be associated with lower efficiency and lower performance when coordination is associated with negative externalities. In these cases, communication may lead to collusive practices, lower efforts and lower organizational performance.

Second, communication is found to have a positive effect in situations with information asymmetries between employer and employee. Communication mitigates moral hazard problems and leads to more trust and trustworthiness in the labor relationship, reflected, for example, in a higher frequency of contract offers, higher wages and higher employee performance. The results of some studies suggest that richer free-form communication is more suited to achieve this positive effect than restricted and limited communication. Moreover, in the context of hidden information about the ability of employees, the results so far suggest that communication improves efficiency when the participation of low-ability employees would be efficiency-enhancing and employers and employees interact bilaterally.

Furthermore, communication is effective in shaping performance under monetary incentive schemes, with positive effects under team incentives but negative effects under tournament incentives. Also, there is evidence for an interaction between communication and performance pay, as the combination of motivational talk and pay-for-performance increases employee performance. At the same time, the evidence on the impact of communication on counterproductive behavior appears to be mixed. On the one hand, communication reduces sabotage among employees, but on the other hand it may facilitate collusive practices which lower performance from the perspective of the company. In public goods settings - resembling teamwork incentives in organization - overall, communication has a positive effect for overcoming free-riding. These positive effects appear to be somewhat weaker in asymmetric environments. In teamwork, communication is also effective when combined with sanctioning mechanisms except when communication is reduced to threats. Surprisingly little research has been performed on the interaction between leadership and communication in public good settings and the existing results are inconclusive.

Overall, the majority of the experimental studies suggest that communication fosters both coordination and cooperation within organizations. As the results show, this can be positive or negative for the organization as a whole depending on the externality created by employee behavior. 
In the light of these results, while the literature on communication in labor settings has been rapidly grown in recent years, there are many unexplored areas of research in which controlled experiments can help to advance our understanding of behavior within organizations.

Up to now, the role of communication has been addressed in a relatively small number of organizational contexts and with respect to a limited range of topics. Hence, there is still large potential to broaden the scope of this research field. An interesting application, for instance, is in the context of remuneration practices. As highlighted in Section 4, although communication is systematically related to the effectiveness of incentive schemes, the respective literature focused explicitly on communication is still small. The existing large experimental literature that does not include communication clearly shows that social preferences shape employees' response to the wages they receive (see Dohmen, 2014, for a survey of the literature). As wages and wage changes are usually communicated to employees by their supervisors, it would be worthwhile to understand whether communication fosters or hinders the process through which wages are accepted, and if so what communication style is most effective.

More generally, many studies show that communication does affect behavior, but there is little systematic evidence about the impact of specific communication channels and content for the processes within organizations. Therefore, it is yet not fully understood why exactly communication works, or under which circumstances. A careful analysis of different communication patterns and of what precisely is communicated could provide researchers with useful insights. As Brandts et al. (2019) suggest, coding software and machine learning techniques might be helpful in this respect. In this context, it would also be interesting to investigate further to what extent content and communication channel interact with each other, and in particular, whether the content of communication systematically depends on the channel through which communication is transmitted.

Most studies reviewed in this paper are based on abstract settings and many of them allow for communication only either via pre-determined messages or via anonymous chat protocols. While this abstraction is important to ensure a high degree of control and has been useful to generate clean results, these modes of communication are relatively impersonal ways of interacting. Since personal relationships are important in the workplace, it seems worthwhile to investigate the impact of more complex forms of communication on the interactions between employers and workers, and within teams of workers. Indeed, some of the reviewed studies on communication in public good settings suggest that free-form or face-to-face communication can be powerful.

Finally, the impact of communication flows is not properly understood. Theoretical work (as mentioned in the introduction to this paper) show that communication flows may have a decisive impact on economic outcomes, such as efficiency and equilibrium selection, but the analysis so far is conducted for relatively simple settings. Here, experimental investigations could help to establish robust behavioral patterns related to strategic interaction within organizations that could be an important input for further theoretical developments. 


\section{References}

Andreoni J, Rao JM (2011) The power of asking: How communication affects selfishness, empathy, and altruism. Journal of Public Economics 95:513-520

Balliet D (2010) Communication and cooperation in social dilemmas: A meta-analytic review. Journal of Conflict Resolution 54:39-57

Ben-Ner A, Putterman L (2009) Trust, communication and contracts: An experiment. Journal of Economic Behavior \& Organization 70:106-121

Berg J, Dickhaut J, McCabe K (1995) Trust, reciprocity, and social history. Games and Economic Behavior 10:122-142

Blume A, Ortmann A (2007) The effects of costless pre-play communication: Experimental evidence from games with Pareto-ranked equilibria. Journal of Economic Theory 132:274-290

Bochet O, Putterman L (2009) Not just babble: Opening the black box of communication in a voluntary contribution experiment. European Economic Review 53(3):309 - 326

Bochet O, Page T, Putterman L (2006) Communication and punishment in voluntary contribution experiments. Journal of Economic Behavior and Organization 60(1):11-26

Bolton G, Werner P (2016) The influence of potential on wages and effort. Experimental Economics 19:535-561

Bolton GE, Chatterjee K, McGinn KL (2003) How communication links influence coalition bargaining: A laboratory investigation. Management Science 49(5):583-598

Bolton P, Dewatripont M (2005) Contract Theory. MIT Press

Brandts J, Cooper D (2007) It's what you say, not what you pay: An experimental study of manager-employee relationships in overcoming coordination failure. Journal of the European Economic Association 5:1223-1268

Brandts J, Cooper D (2018) Truth be told - An experimental study of communication and centralization, Barcelona GSE Working Paper Series - WP No. 1046

Brandts J, Ellman M, Charness G (2016) Let's talk: How communication affects contract design. Journal of the European Economic Association 14:943-974

Brandts J, Cooper D, Rott C (2019) Communication in laboratory experiments. In: Schram A, Ule A (eds) Handbook of Research Methods and Applications in Experimental Economics, Edward Elgar Publishing Ltd., pp 401-418

Cardella E, Depew B (2018) Output restriction and the ratchet effect: Evidence from a real-effort work task. Games and Economic Behavior 107:182-202

Cason T, Sheremeta R, Zhang J (2012) Communication and efficiency in competitive coordination games. Games and Economic Behavior 76:26-43

Cason T, Sheremeta R, Zhang J (2017) Asymmetric and endogenous within-group communication in competitive coordination games. Experimental Economics 20:946-972 
Casoria F, Riedl A (2013) Experimental labor markets and policy considerations: Incomplete contracts and macroeconomic aspects. Journal of Economic Surveys 27:398-420

Charness G (2000) Self-serving cheap talk: A test of Aumann's conjecture. Games and Economic Behavior 33:177-194

Charness G, Dufwenberg M (2006) Promises and partnership. Econometrica 74:1579-1601

Charness G, Dufwenberg M (2010) Bare promises: An experiment. Economics Letters 107:281-283

Charness G, Dufwenberg M (2011) Participation. American Economic Review 101:1211-1237

Charness G, Kuhn P (2011) Lab labor: What can labor economists learn from the lab? In: Ashenfelter O, Card D (eds) Handbook of Labor Economics, vol 4A, 1st edn, Elsevier, pp 229330

Charness G, Rabin M (2005) Expressed preferences and behavior in experimental games. Games and Economic Behavior 53:151-169

Charness G, Du N, Yang CL, Yao L (2013) Promises in contract design. European Economic Review 64:194-208

Chaudhuri A (2011) Sustaining cooperation in laboratory public goods experiments: a selective survey of the literature. Experimental Economics 14(1):47-83

Chaudhuri A, Graziano S, Maitra P (2006) Social learning and norms in a public goods experiment with inter-generational advice. The Review of Economic Studies 73(2):357-380

Cooper DJ, Kagel JH (2005) Are two heads better than one? Team versus individual play in signaling games. American Economic Review 95(3):477-509

Cooper DJ, Kagel JH (2016) A failure to communicate: An experimental investigation of the effects of advice on strategic play. European Economic Review 82:24 - 45

Cooper DJ, Lightle JP (2013) The gift of advice: Communication in a bilateral gift exchange game. Experimental Economics 16:443-477

Cooper R, DeJong D, Forsythe R, Ross T (1992) Communication in coordination games. The Quarterly Journal of Economics 107:739-771

Crawford V (1998) A survey of experiments on communication via cheap talk. Journal of Economic Theory $78(2): 286-298$

Crawford VP, Sobel J (1982) Strategic information transmission. Econometrica 50(6):1431-1451

Dannenberg A (2015) Leading by example versus leading by words in voluntary contribution experiments. Social Choice and Welfare 44(1):71-85

Davies E, Fafchamps M (2017) Pledging, praising and shaming: Experimental labour markets in Ghana, IZA DP No. 10520

Den Hartog DN, Boon C, Verburg RM, Croon MA (2013) HRM, communication, satisfaction, and perceived performance: A cross-level test. Journal of Management 39:1637-1665

Dohmen T (2014) Behavioral labor economics: Advances and future directions. Labour Economics 30:71-85 
Duffy J, Feltovich N (2002) Do actions speak louder than words? An experimental comparison of observation and cheap talk. Games and Economic Behavior 39:1-27

Duffy J, Feltovich N (2006) Words, deeds and lies: Strategic behavior in games with multiple signals. The Review of Economic Studies 73:669-688

Ellingsen T, Östling R (2010) When does communication improve coordination? American Economic Review 100(4):1695-1724

Falk A, Heckman JJ (2009) Lab experiments are a major source of knowledge in the social sciences. Science 326(5952):535-538

Farrell J, Rabin M (1996) Cheap talk. Journal of Economic Perspectives 10(3):103-118

Fehr D (2017) Costly communication and learning from failure in organizational coordination. European Economic Review 93:106-122

Fehr E, Gächter S (2000) Cooperation and punishment in public goods experiments. American Economic Review 90:980-994

Fehr E, Kirchsteiger G, Riedl A (1993) Does fairness prevent market clearing? An experimental investigation. Quarterly Journal of Economics 108:437-459

Goeree J, Zhang J (2014) Communication \& competition. Experimental Economics 17:421-438

Harbring C (2006) The effect of communication in incentive systems - An experimental study. Managerial and Decision Economics 27:333-353

Harbring C, Irlenbusch B (2011) Sabotage in tournaments: Evidence from a laboratory experiment. Management Science 57:611-627

Harris TE, Nelson MD (2007) Applied organizational communication: Theory and practice in a global environment. Routledge

Harrison GW, List JA (2004) Field experiments. Journal of Economic Literature 42(4):1009-1055

Hoppe EI, Schmitz PW (2018) Hidden action and outcome contractibility: An experimental test of moral hazard theory. Games and Economic Behavior 109:544-564

Hutchinson SJ (2014) The importance of communication in fulfilling the strategic role of HRM. In: Miller V, Gordon M (eds) Meeting the Challenge of Human Resource Management, Routledge, chap 2, pp 16-26

Işgin E (2017) Communication versus information transparency in one-shot interactions: A labor market experiment. Managerial and Decision Economics 38:955-963

Isaac RM, Walker JM (1988) Communication and free-riding behavior: The voluntary contribution mechanism. Economic Inquiry 26(4):585-608

Kriss P, Blume A, Weber R (2016) Coordination with decentralized costly communication. Journal of Economic Behavior \& Organization 130:225-241

Kvaløy O, Nieken P, Schöttner A (2015) Hidden benefits of reward: A field experiment on motivation and monetary incentives. European Economic Review 76:188-199 
Levitt SD, List JA (2007) What do laboratory experiments measuring social preferences reveal about the real world? Journal of Economic Perspectives 21(2):153-174

Levitt SD, List JA (2009) Field experiments in economics: The past, the present, and the future. European Economic Review 53(1):1 - 18

Masclet D, Noussair CN, Villeval MC (2013) Threat and punishment in public good experiments. Economic Inquiry 51(2):1421-1441

Mohlin E, Johannesson M (2008) Communication: Content or relationship? Journal of Economic Behavior \& Organization 65:409-419

Oprea R, Charness G, Friedman D (2014) Continuous time and communication in a public-goods experiment. Journal of Economic Behavior and Organization 108:212-223

Ostrom E, Walker J, Gardner R (1992) Covenants with and without a sword: Self-governance is possible. American Political Science Review 86:404-417

Pogrebna G, Krantz DH, Schade C, Keser C (2011) Words versus actions as a means to influence cooperation in social dilemma situations. Theory and Decision 71(4):473-502

Riedl A, Rohde IM, Strobel M (2016) Efficient coordination in weakest-link games. Review of Economic Studies 83:737-767

Schotter A (2003) Decision making with naive advice. American Economic Review 93(2):196-201

Sutter M, Strassmair C (2009) Communication, cooperation and collusion in team tournaments An experimental study. Games and Economic Behavior 66:506-525

Van Huyck JB, Battalio RC, Beil RO (1990) Tacit coordination games, strategic uncertainty, and coordination failure. American Economic Review 80:234-248

Zelmer J (2003) Linear public goods experiments: A meta-analysis. Experimental Economics 6:299310 